\title{
Esportes surdos na constituição do ser social: uma compreensão histórica sob a perspectiva da Educação Ambiental
}

\author{
Marco Aurélio Rocha Di Franco* \\ Simone dos Santos Paludo** \\ Tatiana Bolivar Lebedeff***
}

\section{Resumo}

A inclusão social dos surdos é um complexo fenômeno que engloba questões de cunho moral, conceitual, legal, entre outros. Neste caminho, a principal conquista dos surdos foi, sem dúvida, a oficialização da sua língua como língua oficial brasileira, que é fator de identificação, cultura e socialização para os surdos. Já o esporte teve vultoso papel no processo de organização e de transformação subjetiva dos surdos, o que, no contexto da Educação Ambiental, o caracteriza como ferramenta de modificação dos ambientes físicos e psicossociais por onde os surdos transitam, à medida que promove a autoestima dos indivíduos, a autonomia dos grupos e o reconhecimento dos demais. O objetivo deste estudo é evidenciar o papel do esporte como ferramenta de socialização e de construção de identidade surda e indicar que os esportes são um motivo e meio de inserção e de modificação das relaçôes político-sociais dos surdos no Brasil.

Palavras-chave: Surdos; Esportes; Inclusão social; Educação Ambiental.

* Professor da Universidade Federal de Rio Grande. Rio Grande, Rio Grande do Sul, Brasil.

** Professora doutora da Universidade Federal de Rio Grande. Rio Grande, Rio Grande do Sul, Brasil.

*** Professora doutora da Universidade Federal de Pelotas. Pelotas, Rio Grande do Sul, Brasil. 


\section{Deaf sports in the constitution of the social being: an historical review from the perspective of Environmental Education}

\section{Abstract}

The social inclusion of deaf people is a complex phenomenon that encompasses moral, conceptual, and legal issues, among others. In such way, the main achievement of the deaf was undoubtedly formalizing their own language as a Brazilian official language, which is a matter of identification, culture and socialization for the deaf. Also, sports had a significant role in the organization and subjective transformation process of the deaf which, in the context of Environmental Education, characterizes them as a tool for modifying the physical and psychosocial environments where the deaf transit as it promotes self-esteem of each individual, the autonomy of the groups, and recognition from others. The aim of this study was to highlight the role of sports as a socialization and construction of the deaf identity tool and showed that sports were the cause and means of insertion and modification of political and social relations of the deaf in Brazil.

Keywords: Deaf sports; Social inclusion; Environmental Education.

\section{Introdução}

Os surdos convivem em uma sociedade onde a maioria é ouvinte, que utiliza como língua o Português, uma língua de modalidade oral-auditiva e, por isso precisam desenvolver estratégias para sobreviver em seu meio. A Língua Brasileira de Sinais (Libras), língua nativa dos surdos brasileiros, é uma língua cuja modalidade é, de acordo com Strobel, (2008) espacial-visual. Portanto, o modo de viver, de interagir e de compreender o mundo é diferente dos ouvintes. Pode-se dizer que a Cultura Surda é o conjunto de adaptaçôes, vivências, experiências, significados que permeiam as relaçóes do povo surdo com o mundo em que vivem. Dentre os artefatos da Cultura Surda, podem ser destacados: a experiência visual, a língua, os relacionamentos familiares, a literatura surda, a vida social e esportiva, as artes visuais, a política, os materiais, entre outros (STROBEL, 2008, p. 67). Todos eles são fundamentais para a constituição identitária dos sujeitos surdos em relação ao mundo ouvinte.

O esporte surdo é um artefato cultural de extrema importância para a comunidade surda. A organização dos surdos em atividades esportivas tem registros, que datam do século XIX (SARMENTO, 2013, p. 340) como o primeiro clube de futebol surdo do mundo, o Glasgow DF no Reino Unido, a associação Sports Club for the Deaf de 1888, em Berlim e o primeiro clube desportivo para surdos na França, o Club Cycliste des sourds-muets de 1899. Posteriormente, no início do século XX, muitas outras associações desportivas foram criadas ao redor do mundo.

No Brasil, de acordo com Monteiro (2006), as associaçóes desportivas tiveram sua origem no Grêmio Esportivo fundado em 1930, no Instituto Nacional de Educação de Surdos (INES). O INES, que data de 1856, na década de 30, foi a única 
escola de surdos no país a congregar um número muito expressivo de surdos vindos de diversas partes do Brasil. O Grêmio Esportivo do INES foi responsável por elaborar ou adaptar regras de esportes e desportos e organizar competiçôes internas em que a maioria, se não todos dos alunos, participavam com grande interesse. Estes eram importantes eventos de confraternização e interação entre surdos que promoviam a integração social daqueles indivíduos. Ocorre que, ao concluírem seus estudos no INES e retornarem à sua terra de origem, muitos surdos sentiam falta dos eventos esportivos e sociais promovidos pelo Grêmio Esportivo e sentiam-se impelidos pelo desejo de retomar e ampliar as possibilidades de convivência entre surdos, então fundaram várias associaçôes de surdos Brasil afora.

Muitas dessas associaçôes existem desde aquela época, posteriormente, outras foram fundadas e algumas já se extinguiram mas, apesar das inconstâncias estruturais e organizacionais, deve-se às associaçóes muitas vitórias conquistadas pelos surdos no âmbito político e social. As associaçóes, comenta Monteiro (2006), figuram como fortes organizaçóes nas quais os surdos somam forças para lutar por seus direitos, para consolidar sua cultura, para conviver com semelhantes e para confraternizar.

Em muitas confraternizaçôes o esporte aparece como diversão, nos jogos de Pingue-Pongue durante jantares e até em competiçôes exclusivas de surdos em que o esporte é o cenário principal. Percebe-se, entâo, uma colaboração recíproca e integrada entre eventos esportivos e associaçóes de surdos, tendo em vista que as associações surgiram por causa dos eventos esportivos. Os jogos esportivos são táo importantes na vida dos surdos que houve a necessidade de articular as associaçóes de maneira a controlar e melhor promover estes eventos, já que muitas vezes as atividades transpóem fronteiras de municípios e estados. Diante dessas peculiaridades foi, então, percebida a necessidade de organizar as associaçóes para eventos esportivos em instâncias estaduais, fundando-se, assim, as federaçôes esportivas (CBDS $\left.{ }^{1}, 2013\right)$.

Percebe-se que os esportes tiveram, e ainda tem, o trunfo de modificação dos ambientes sociais dos quais os surdos participam e este é o foco desse artigo: evidenciar o papel do esporte como ferramenta de socialização e de construção de identidade surda a partir dos referenciais da Educaçáo Ambiental.

\section{Surdez e Ecologia Mental}

A participação social dos surdos foi, no passado, quase nula. As barreiras de comunicação eram invencíveis, os surdos eram obrigados a se comportar como ouvintes, sendo submetidos a desenvolver a "fala", ou seja, a oralização, principal premissa do Método Oralista. Em 1880, em Miláo na Itália, ocorreu o Congresso Internacional de Educação para Surdos que definiu a preferência do Método Oral ao invés do uso de sinais para a educação e ensino dos surdos (INES, 2011). O Congresso foi preparado pela militância oralista com o propósito definido de dar força à lei e a suas posiçôes com respeito à surdez e à educação dos surdos. De acordo com Sánchez (1990), o Congresso de Miláo pode ser considerado um marco, inaugurando oficialmente a tese sustentada pela corrente oralista, segundo a qual os surdos deveriam falar como ouvintes, proibindo o uso da Língua de Sinais a qual ficou vista como uma marca 
infame, e exigindo o domínio da língua oral como condição sine qua non para ser aceito na comunidade majoritária.

Assim, segundo Sánchez (1990), durante os 100 anos de predomínio oralista, a prática pedagógica baseou-se, por um lado, na estruturaçáo gramatical da fala e, por outro, na articulaçáo, leitura labial e, mais recentemente, no treinamento auditivo. Moura (1996) ressalta que independentemente da técnica utilizada, tais como, oralismo puro, método multissensorial, método unissensorial, entre outros, a principal bandeira era a não permissão do uso da Língua de Sinais. As condiçóes de trabalho eram precárias, comenta Goldfeld (2001), o acesso à comunicação em locais públicos inexistente, enfim, os surdos não eram protagonistas da própria história.

Esta exclusão é refletida em diversos aspectos da subjetividade surda, especialmente no fantasma do Oralismo, porém, à luz da Ecologia Mental, Guattari (2001), os surdos produziram mudanças e se autoconstruíram, tendo a sua língua como ponto de ruptura, de denotaçáo e de significaçáo da sua humanidade.

O fracasso do oralismo e uma série de acontecimentos ocorridos na década de 60 iniciaram a uma mudança de percepção da surdez. A partir desse período, incorporam-se ao campo da surdez novos conhecimentos provenientes de outras disciplinas, fundamentalmente da linguística, da psicolinguística e da sociolinguística que, de acordo com Sánchez (1990), romperam com o predomínio da concepção médica. O autor salienta que os estudos iniciados na época comprovaram, claramente, a complexidade do processo de aquisiçấo da linguagem e, com isso, tornou-se visível a impossibilidade de ensinar mecanicamente a língua oral por sucessivas repetiçóes de estímulos e resposta. Para Sánchez, os surdos foram percebidos não como doentes ou deficientes, mas foram vistos como membros de uma comunidade linguística minoritária, para a qual formação e existência são inevitáveis e obrigatórias, dadas as peculiaridades da comunicaçáo de seus integrantes.

Nesta mesma época, particularmente nos Estados Unidos, mas também, em maior ou menor número, no resto do mundo, ocorre o chamado Movimento Multicultural, que englobou grupos minoritários étnicos, como negros, latinos, índios e se estendeu às pessoas com necessidades especiais, que não queriam mais ser consideradas como cidadãos de segunda classe, de acordo com Moura (1996). A autora ressalta que o movimento surdo ganha respaldo no Multiculturalismo e, segundo Sánchez (1990), pela pressáo desses grupos, que contaram com apoio de vastos setores da sociedade, os quais produziram mudanças em alguns casos rápidas e profundas.

Neste ambiente renovador, os surdos encontraram o caminho para reivindicar o uso da Língua de Sinais na educação, o que repercutiu na proposta da Comunicação Total como Filosofia Educacional. A Comunicação Total possuía como premissa básica a utilização de toda e qualquer forma de comunicaçấo com a criança surda, de tal modo que nenhum método ou sistema particular deveria ser omitido ou enfatizado. Para tanto, eram utilizados gestos naturais, língua de sinais, alfabeto digital, expressão facial, tudo acompanhado com a fala. 
Posteriormente no Brasil, com maior referência a partir da década de 90 do século XX, a Comunidade Surda ${ }^{2}$ e o Movimento Surdo ${ }^{3}$ intensificaram a exigência pela presença da Língua de Sinais na Escola, não como língua coadjuvante, mas como primeira língua, reivindicando o Bilinguismo. Sánchez (1990) ressalta que a educação bilíngue para surdos deve basear-se na utilização plena da língua de sinais para garantir o desenvolvimento intelectual e de linguagem, para aperfeiçoar o bom emprego desses na aprendizagem escolar e para facilitar o conhecimento da língua falada nas suas formas oral e escrita. Isso significa dar à criança surda as mesmas possibilidades psicolinguísticas da criança ouvinte. Terra (2011) comenta que a Ecologia Mental é baseada na subjetividade, o mundo interno do ser humano, a qual é o conjunto de sentimentos e pensamentos que vai influenciar na maneira como ele vai se relacionar com o mundo externo. Para Terra, a percepção de ser diferente e a aquisição de sua língua são dois processos, entre outros, que constituem a subjetividade. A língua é um dos meios pelo qual se processa a subjetividade e, para Terra, no caso dos surdos, a língua é diferente da maioria, assim como o surdo é diferente da maioria. A autora destaca, na Ecologia Mental, que a construção das identidades surdas será favorecida pelo estímulo a Libras e pela percepção de si mesmo.

No Brasil, o movimento surdo, através das Associações de Surdos, alcançou conquistas reconhecidas internacionalmente. A principal delas foi o reconhecimento oficial da Libras, através da Lei de LIBRAS, n. 10.436 (BRASIL, 2002). Em 2005, foi despachado o Decreto 5.626 (BRASIL, 2005), que regulamenta a utilizaçáo da Língua, assegurando o direito à presença de intérpretes em atos públicos, na educaçáo, entre outras demandas. Nesse cenário, comenta Lima (2006), torna-se obrigatório o ensino da LIBRAS em cursos de licenciatura, entre outros aspectos que foram fundamentais para a mudança de postura dos surdos diante da sociedade.

Ao articular a lei que regulamenta a língua de sinais e as ideias presentes nas três ecologias de Guattari, pode-se perceber que a língua de sinais consegue libertar os surdos do seu maior fantasma, o oralismo, possibilitando assim uma saída da posição passiva que muitos ocupavam. A este respeito, Bisol, Valentini, Simioni e Zanchin (2010) informam que o advento da Lei de Libras paulatinamente trouxe mudanças na atitude dos surdos, que passaram a frequentar mais escolas e universidades e a utilizar sua língua para modificar os ambientes onde vivem, adquirindo o respeito dos ouvintes e dos demais surdos, além de servirem de exemplo para que outros surdos também conquistassem sua cidadania.

Dessa forma, os surdos começaram a escrever páginas e mais páginas de importantes fatos históricos e não cessam de ocorrer e promover mais e mais transformaçóes sociais, iniciando-se pelo próprio ingresso de surdos no mercado de trabalho na área do ensino, tornando-se professores de crianças surdas. Tal feito é considerado positivo para que elas possam iniciar o processo de alfabetizaçáo a partir de experiências sinalizadas e construam modelos e referenciais adultos de seus pares, afirma Lodi, (2005, p. 419).

Contextualizando as práticas esportivas neste processo, é possível perceber que os esportes sempre estiveram presentes durante toda a história das organizações polí- 
ticas e sociais dos surdos, ainda que não existam muitos registros oficiais publicados até o momento sobre o assunto. Ladd (2011) comenta que o esporte surdo tem sido fundamental no "recrutamento" de jovens surdos para a comunidade surda, inclusive para aqueles que foram dissuadidos pelo Oralismo a participarem de Associaçóes de Surdos. Todavia, esta relação pode ser percebida ao observar-se o caráter social do esporte através dos tempos e das comunidades de variadas peculiaridades, inclusive a dos surdos, como discutiremos a seguir.

\section{esporte como fator de empoderamento social}

Esporte é o termo utilizado para designar os exercícios físicos realizados individual ou coletivamente que obedecem a regras e não tem fim utilitarista. Proni e Lucena (2002) e Duarte (2003) narram que esportes são praticados desde as mais remotas épocas da humanidade, quando, em registros muito antigos, os homens primitivos competiam com a caça e com lutas. Tempos depois, os homens concorriam para adquirir status e poder diante da sociedade, ou ainda para produzir fronteiras culturais, como no caso do Futebol Americano, criado para produzir uma "americanizaçáo" da cultura inglesa e, então, fazer o caminho inverso da colonização e implantar-se comercialmente na Inglaterra a partir dos Estados Unidos.

Nessa época, os atletas começaram a prática de exercícios físicos com o intuito de preparar os corpos para as competiçóes, os primeiros treinamentos físicos. Quando chegaram os períodos de guerras, os povos cujos militares participavam de competiçóes tinham melhores performances nos campos de batalha. Assim, instituíram-se as escolas de ginástica nos países com maior participação nas guerras ou com mais disputas de interesses ocorrendo em fronts, assim afirmam Sigoli e Rose Junior (2004).

Sigoli e Rose Júnior ainda comentam que as Escolas de Ginásticas tinham o objetivo principal de preparar os homens para as guerras, pois acabavam por mostrar que são os mais bem preparados e além de terem mais resistência para os confrontos, recuperavam-se mais rapidamente de ferimentos e doenças adquiridas durante as batalhas. Essa descoberta chamou a atenção para a validade da prática de exercícios físicos como promoção de saúde. Até então, várias modalidades esportivas haviam sido criadas e eram praticadas por pessoas das mais diversas classes sociais com fins de socialização e entretenimento de plebeus e de nobres.

Após o término das guerras mundiais, o esporte é praticado com finalidades múltiplas, e não é por acaso que está inserido nos Parâmetros Curriculares Nacionais (PCN) através da Educação Física escolar. As diversas modalidades hoje existentes e as inúmeras transfiguraçóes possíveis realizadas por grupos (escolas, vizinhanças, grupos culturais, entre outros) fazem dos eventos esportivos acontecimentos comuns em ambientes dos mais variados tipos, assegura Betti (2002). Variam, também, as funçóes dadas aos exercícios esportivos, mas pode-se, seguramente, afirmar que o esporte é um forte incentivador social na atualidade, conforme Betti e Zulani (2002) e Sigoli e Rose Júnior (2004). 
O esporte está ligado às competições, principalmente aos jogos Olímpicos, que congregam a maioria das modalidades praticadas desde 776 a.C.. O esporte, em geral, nem sempre foi para "todos", inclusive servia para determinar quem era mais forte e condecorar com poder os vencedores das provas. Assim, desde sempre, sobre as pessoas com deficiência, ainda que não conste registros de sua exclusão, fica provado pelo não-registro de sua inclusão em competiçôes esportivas antigas, de acordo com Duarte (2003).

O primeiro grupo de pessoas com deficiência a promover competiçôes esportivas adaptadas foram os surdos a partir de 1924, quando realizaram os primeiros Jogos Olímpicos para Surdos na França. Os jogos seguintes aconteceram de quatro em quatro anos, da mesma forma como os Jogos Olímpicos Internacionais, mas sem qualquer vínculo ou relação entre eles, a não ser a inspiraçáo dos primeiros nos segundos, dessa forma descreve Cardoso (2010).

O esporte adaptado, de maneira geral, procura oferecer condiçóes igualitárias de participação para os deficientes. Isto implica em modificações, por exemplo, de altura de rede para a prática do Voleibol para deficientes de membros inferiores; de uso de bola com guizos para produzir som para os cegos praticarem Futebol; de participação de corredor-guia para cegos competirem no Atletismo; de prática do Golbol para cegos (similar ao handball, mas sentados em quadra); da existência de natação para deficientes de membros superiores; de uso de cadeira de rodas esportiva para possibilitar que deficientes de membros inferiores pratiquem Basquetebol, Hóquei, Curling, Boxe, Tênis, corridas de velocidade, entre outros. Todavia, essas adaptaçóes exigem poucas mudanças nas regras, e a forma de proceder da arbitragem ocorre quase sem alteraçóes, pensa Sousa e Costa (2004).

Diferente é o caso dos esportes surdos, que não exigem os mesmos ajustes. As modalidades praticadas por eles precisam sofrer adequaçôes de arbitragem, já que o uso de apitos, sirenes e demais sinais sonoros não cabe para os surdos. Dessa forma, faz-se necessário o uso de sinalizadores visuais, por meio de implementos coloridos usados com movimentos vigorosos ou de sinais luminosos. Inspire-se com a Nataçáo, que requer lâmpadas instaladas no fundo da piscina para que os surdos percebam o momento da autorização da largada para a prova; com a necessidade de domínio de Língua de Sinais pelos árbitros ou da presença de intérpretes durante as provas e partidas em geral; com o uso de bandeiras coloridas em lugar dos apitos.

No Brasil, a fundação da Confederação Brasileira de Desportos de Surdos (CBDS) garantiu o direito de os surdos terem espaço no universo esportivo, mas num nicho cultural peculiar, marcado pela comunicação majoritariamente em LIBRAS e com adaptaçóes pertinentes de sinalizaçóes de arbitragem e afins, é exemplo prático da vivência da Ecologia Social, sugerida por Guattari (2001). Na década de 50, os surdos viviam um período de articulaçôes sociais e políticas, fundando associaçóes que serviam de sedes para encontros e práticas esportivas, que acompanhavam o momento nacional de fomento a essas práticas, uma vez que o presidente Getúlio Vargas havia recém-criado o Conselho Nacional de Desportos (CND). Estas ocasiôes tornaram-se mais frequentes nas associaçóes e multiplicavam-se as competiçôes que, inicialmente, eram focadas na modalidade Futebol, conforme consta na CBDS (2013). 
No dia 20 de janeiro de 1959, SentilDelatorre liderava a fundação de uma entidade que organizasse exclusivamente esportes dos surdos. Era a "Federação Carioca de Surdos-Mudos" (FCSM), que atuava regionalmente e fora reconhecida pela CND, pela Confederação Brasileira de Futebol (CBF) e, posteriormente, filiada ao Comitê Internacional de Esportes Surdos (CISS) e permanece ligada ao CISS, de acordo com o registro na CBDS (2013). Com a boa atuação da FCSM em sua regiâo, os surdos de todo o país desejaram que a instituição fosse atuante em toda a nação. Entâo, em 17 de novembro de 1984, no auditório do INES, Delatorre convocou uma assembleia, na qual fundaram a CBDS, que foi presidida inicialmente por Mário Júlio de Mattos Pimentel e durante seu mandato adquiriu-se a sede da confederaçáo em São Paulo. Posteriormente, SentilDelatorre também presidiu a CBDS, assim como outros presidentes, informa a CBDS (2013).

A CBDS promoveu e acompanhou competições nacionais e internacionais em diversas modalidades, nas quais as seleçôes brasileiras de futebol de campo masculino, voleibol feminino, de tênis de mesa e de atletismo se sagraram campeãs, consta em CBDS (2013). Um fato importante é a realização da I Olimpíada dos Surdos no Brasil, em maio de 2002, na cidade de Passo Fundo, Rio Grande do Sul. O evento contou com a participação de vinte e nove delegaçóes vindas de nove estados e com mil e quinhentos atletas. Foram disputados esportes individuais e coletivos nas categorias feminina e masculina.

Ladd (2011) comenta que, de maneira geral, quando ocorrem campeonatos entre diferentes Associaçóes de Surdos, não é apenas a equipe que joga e viaja, pelo contrário, muitos surdos participam das excursóes, acompanhando seus times. Entretanto, o objetivo central não é acompanhar os jogos, mas sim, garantir a oportunidade de criar redes com outras pessoas surdas nas localidades onde ocorrem os jogos, para trocar informaçóes, para procurar companheiros afetivos, para encontrar-se com amigos ou, ainda para consolidar suas redes sociais.

Deste modo, pode-se considerar o esporte como um elo fundamental entre os surdos, incentivando-os a adquirir sua própria língua no contato com seus semelhantes, pois a participação vai além do desenvolvimento físico; as relaçóes vão permitir a comunicação e uma gama de informaçôes fundamentais para a consolidação de sua identidade como surdo. Para Castells (1999) entende-se por identidade a fonte de significado e experiência de um povo. Além disso, ao falar de autores sociais, entende por identidade "o processo de construção de significado com base em um atributo cultural, ou ainda um conjunto de atributos culturais inter-relacionados o(s) qual(ais) prevalece $(\mathrm{m})$ sobre outras fontes de significado" (CASTELLS, 1999, p. 85) Pode-se compreender a surdez, portanto, como um marcador cultural que posiciona e diferencia indivíduos, estabelecendo redes de reconhecimento e pertencimento constituídos pela experiência visual materializada em uma língua, em traços e lutas compartilhadas.

Esta identidade é o trunfo para que os surdos reconheçam-se com seus pares e fortaleçam, assim, suas comunidades e sua subjetividade, consolidem sua organização e sua participação política na sociedade em geral, que já mostra evidentes modifica- 
çôes quanto ao reconhecimento e valorização da surdalidade ou DeafGain. Martins e Klein (2012) explicam que as conquistas, a importância, o benefício e a contribuição que os surdos adquiriram até o presente por serem surdos podem ser considerados sinais de mudanças ambientais, bem propícias a intervençôes de educação ambiental.

\section{A Educação Ambiental e o ser surdo}

Terra (2011) fundamenta seu trabalho com os surdos a partir das teorias das três Ecologias e ajuda a formar paralelos entre o que Guattari (2001) percebe da sociedade em geral e a essa formada pelos e com os surdos, com suas características intrínsecas, marcadas pelas identidades surdas e sua forma de interaçáo social de surdos com ouvintes e de surdos com surdos.

Guattari baseia sua teoria sobre as Ecologias na percepção de deterioração das relaçóes sociais, desde redes de parentesco, passando pela vida doméstica, conjugal e familiar devido à padronizaçáo dos comportamentos, que torna os convívios impessoais, de forma que a intimidade é perdida e há pouco diálogo, pouca troca de experiências, poucas confraternizaçóes. Apesar de sólida, a teoria de Guattari sobre a infantilização das relaçóes sociais não caracteriza a realidade das relaçóes entre os surdos, que vem passando por um processo inverso, conquistando independência social e construindo novas relaçóes afetivas sejam elas no contexto da família ou da comunidade, de acordo com Dizeu e Caporali (2005).

A comunidade surda caminha no sentido de reconstrução do seu contexto histórico, visto que as frentes de defesa do uso de Libras têm como principal argumento o fato de que a língua une os surdos e os identifica como comunidade culturalmente definida, também como ocorre com comunidades indígenas e de colonizaçôes européias, por exemplo. Uma mesma perspectiva ético-política atravessa, afirma Guattari (2001), as questôes do racismo, do falocentrismo, dos desastres legados por um urbanismo que se queria moderno, de uma criaçáo artística libertada do sistema de mercado, de uma pedagogia capaz de inventar seus mediadores sociais, etc. Tal problemática, no fim das contas, é a da produção de existência humana em novos contextos históricos, Guattari aponta:

A questão será literalmente reconstruir o conjunto das modalidades do ser-em-grupo. E não somente pelas intervençôes "comunicacionais", mas também por mutaçôes existenciais que dizem respeito à essência da subjetividade. Nesse domínio, não se ateriam às recomendações gerais, mas fariam funcionar práticas efetivas de experimentaçáo tanto nos níveis microssociais quanto em escalas institucionais maiores. (GUATTARI, 2001, p. 16).

Esta ideia fundamenta as açôes surdas de manifestações culturais apesar ou por causa de sua identidade, que se traduzem em seus hábitos e suas estratégias de convivência, como em promoçóes de eventos de surdos, congressos, encontros, campeonatos esportivos, cultos religiosos, cinema surdo, teatro surdo, etc. 
Guattari defende, ainda, que a moda e a mídia definem grande parte dos hábitos e manifestaçóes sociais em geral. Os surdos, nesse contexto, andam na contramão, como evidenciam Dizeu e Caporali (2005), pois lutam por construir novas "modas", nova opinião da publicidade e da sociedade em geral e não querem antídoto algum para todas as suas conquistas. Sobre a questão da diferença, Guattari comenta que:

Convém deixar que se desenvolvam as culturas particulares inventando-se, ao mesmo tempo, outros contatos de cidadania. Convém fazer com que a singularidade, a exceção, a raridade funcionem junto com uma ordem estatal o menos pesada possível. (GUATTARI, 2001, p. 35).

A inclusão social, desejada pelos surdos, concentra-se na acessibilidade linguística e no direito de participar de eventos públicos como todos os cidadãos. No caso dos surdos, em relação aos diversos ambientes em que eles transitam, existe uma diferença crucial na maioria dos espaços, a língua. As relaçóes que se estabelecem nestes espaços acabam por influenciar completamente na sua subjetividade, na maneira como ele entende o mundo e na forma em que vai reagir a partir de entáo. Os elementos que sáo incorporados ou que formam as subjetividades advêm das várias experiências de sociabilidade pelas quais passam, a família, a escola, os colegas e amigos, a comunidade local, a igreja e, especialmente de maneira cada vez mais significativa, os meios de comunicação social. Articular, portanto, as relaçôes sociais dos surdos à sua participação nos esportes ainda é um desafio, conferindo a estes momentos uma significativa contribuição para que ele possa situar-se, estruturar-se e adaptar-se a um mundo do qual náo faz parte, o mundo dos ouvintes. Ser aceito em um grupo do qual não faz parte é uma tarefa assustadora e, muitas vezes, frustrante.

Finalizando a discussão sobre a ecologia social, é importante salientar que a mesma está tangenciada às relaçôes dos seres humanos entre si, as relaçóes geradas na vida em família, entre amigos, na escola, no bairro, na cidade, entre os povos, entre as naçôes. A ecologia social retrata a qualidade destas relaçóes. Em sua pesquisa sobre identidades surdas, Terra (2011) apresenta ligaçôes estabelecidas entre a ecologia social e a construção das identidades surdas representadas através de cinco subcategorias, o relacionamento com o outro, o encontro surdo com surdo, o trabalho com os pais, a cautela com o implante coclear e o papel do professor surdo. No caso dos esportes surdos, as possibilidades de construção de identidades surdas são empoderadas pelo relacionamento com o outro e com o encontro surdo-surdo.

\section{Considerações finais}

É notória a influência dos esportes, como organizaçôes esportivas, para a construção da subjetividade social dos surdos através dos tempos, fazendo-os transcender desde uma posiçáo submissa e anulada para situaçóes de liderança e de autonomia em âmbitos comunitários e nacionais. Como salienta Ladd (2011), o esporte surdo é o locus onde se encontra de maneira mais expressiva a autonomia surda. Além disso, Sarmento (2013) comenta que, durante muitos anos, o esporte surdo foi uma das rotas de entrada para a vida na comunidade surda. 
No esporte surdo a identidade cultural,

[...] surge como componente chave, que motiva o desejo dos surdos em manterem os seus próprios eventos desportivos, sejam eles olímpicos, internacionais, nacionais ou regionais onde as suas necessidades e aspiraçóes possam ser preenchidas. (SARMENTO, 2013, p. 345)

Tendo em vista a discussão sobre as relaçôes entre esporte surdo e Educação Ambiental, sugere-se que o esporte surdo possua um papel importantíssimo na inserção de surdos na comunidade surda e na possibilidade de compreensão dos mesmos, neste locus privilegiado da sua língua, da sua identidade e da sua cultura. As relaçóes entre a ecologia social e a construçáo das identidades surdas explicitam que as possibilidades de construção de identidades surdas são empoderadas pelo relacionamento com o outro e com o encontro surdo-surdo.

Outros estudos de cunho histórico são necessários para produzir registros oficiais da trajetória dos surdos no meio esportivo, além disso, investigaçôes na área da Educação Ambiental articulada com os esportes poderão ser úteis para que as práticas e os eventos esportivos sejam espaços de intervençóes, fomentando o desenvolvimento humanístico, político e social dos surdos.

\section{Referências:}

BETTI, M. et al. Educação física escolar: uma proposta de diretrizes pedagógicas. Revista Mackenzie de Educaçáo Física e Esporte, Bauru, ano 1, n. 1, p. 73-81, 2002.

BISOL, C. A. et al. Estudantes surdos no ensino superior: refexões sobre a inclusão. Cad. Pesq. v. 40, n. 139, p. 147-172, jan./abr. 2010.

BRASIL. Lei n. 10.436, de 24 de abril de 2002. Dispóe sobre a língua brasileira de sinais - Libras e dá outras providências. Brasília: Presidência da República, 2002.

Decreto n. 5626, de 22 de dezembro de 2005. Regulamenta a Lei n. 10.436, de 24 de abril de 2002. Dispóe sobre a língua brasileira de sinais - Libras, e o art. 18 da Lei n. 10.098, de 19 de dezembro de 2000. Brasília: Presidência da República, 2005.

CARDOSO, V. D. A reabilitação de pessoas com deficiência através do desporto adaptado. Rev. Bras. Ciênc. Esporte, Florianópolis, v. 33, n. 2, p. 529-539, abr./jun. 2011-2010.

CASTELLS, M. O poder da identidade. São Paulo: Paz e Terra,1999.

CBDS: uma história de sucesso. Disponível em: <http://www.cbds.org.br/historia.php>. Acesso em: 12 jan. 2013.

DIZEU, L. C. T. B. et al. A língua de sinais constituindo o surdo como sujeito. Educ. Soc., Campinas, v. 26, n.91, p. 583-597, maio/ago. 2005. Disponível em: <http://www.cedes.unicamp.br>. Acesso em: 27 set. 2008.

DUARTE, O. História dos esportes. 4. ed. São Paulo: Senac, 2003.

GOLDFELD, M. Breve relato sobre a educação de surdos. In: numa perspectiva sócio-interacionista. São Paulo: Plexus, 2001.

A criança surda: linguagem e cognição

GUATTARI, F. As três ecologias. 11. ed. Campinas: Papirus, 2001.

INES. Instituto Nacional de Educação de Surdos. Disponível em: <http://www.ines.gov.br>. Acesso em: mar. 2011.

KLEIN, M. A formaçáo do surdo trabalhador: discursos sobre a surdez, a educaçáo e o trabalho. 1999. Dissertação (Mestrado em Educação) - Programa de Pós-Graduação em Educaçáo, Faculdade de Educação, Universidade Federal do Rio Grande do Sul, Porto Alegre, 1999. 
LADD, P. Comprendiendola cultura sorda: en busca de lasordedad. Concepción: ImpresoConcepción, 2011.

LIMA, E. S. Discurso e identidade: um olhar crítico sobre a atuação do(a) intérprete de libras na educaçáo superior. 2006. 163 f. Dissertação (Mestrado em Linguística) - Programa de Pós-Graduação em Linguística, Departamento de Linguística, Línguas Clássicas e Vernácula, Universidade de Brasília, Brasília, 2006.

LODI, A. C. B. Plurilingüismo e surdez: uma leitura bakhtiniana da história da educação dos surdos. Educaçáo e Pesquisa, São Paulo, v. 31, n. 3, p. 409-424, set./dez., 2005.

MARTNS, F. C. e KLEIN, M. Audismo e deafgain: experiências de sujeitos surdos. Disponível em: <http:// www2.ufpel.edu.br/enpos/2012/anais/pdf/CH/CH_00326.pdf>. Acesso em: 22 jul. 2014.

MONTEIRO, M. S. História dos movimentos dos surdos e o reconhecimento da Libras no Brasil. ETD - Educaçáo Temática Digital, Campinas, v. 7, n. 2, p. 292-302, jun. 2006. ISSN: 1676-2592.

MOURA, M. C. de. O surdo: caminhos para uma nova identidade. São Paulo: PUC, Tese de Doutoramento, 1996.

PRONI, M. W. et al. Esporte: história e sociedade. Campinas: Autores Associados, 2002.

SÁNCHEZ, C. La increible y triste historia de lasordera. Caracas: CEPROSORD, 1990.

SARMENTO, F. Os surdos no desporto. In: COELHO, O. e KLEIN, M. (Coord.). Cartografias da surdez: comunidades, línguas, práticas e pedagogia. Porto: Livpsic, 2013.

SIGOLI, M. A. et al. A história do uso político do esporte. Revista Brasileira de Ciência e Movimento. Brasília, v. 12, n. 2, p. 111-119, jun. 2004.

SOUSA, S.; COSTA, A. Educação física e esporte adaptado: história, avanços e retrocessos em relação aos principios da integraçẫo/inclusão e perspectivas para o século XXI. Uberlandia: Revista Brasileira. Ciencias. Esporte, 2004.

STROBEL, K. L. As imagens do outro sobre a cultura surda. Florianópolis: Ed. da UFSC, 2008.

TERRA, C. L. O processo de constituiçáo das identidades surdas em uma escola especial para surdos sob a ótica das Três Ecologias. 2011. 186 f. Dissertação (Mestrado em Educação Ambiental) - Pós-Graduação em Educação Ambiental, Universidade Federal de Rio Grande, Rio Grande, RS, 2001.

\section{Notas}

${ }^{1}$ Informaçôes contidas no hipertexto de apresentação da CBDS.

2 De acordo com Strobel (2009), Comunidade Surda é um grupo de pessoas que vive em um determinado local, partilha de objetivos comuns e, por diversos meios trabalham para alcançar esses objetivos. Uma comunidade Surda inclui surdos e ouvintes, tais como membros da família, intérpretes, professores, entre outros.

${ }^{3}$ Os movimentos surdos são "entendidos como movimentos sociais articulados a partir de aspiraçốes, reivindicaçôes, lutas das pessoas surdas no sentido do reconhecimento de sua língua, de sua cultura” (Klein, 1999).

\section{Correspondência}

Marco Aurélio Rocha Di Franco - Universidade Federal do Rio Grande. Avenida Itália, KM 8, Carreiros. CEP: 96201-900 - Rio Grande, Rio Grande do Sul - Brasil.

E-mail: marcodifranco@terra.com.br - simonepaludo@yahoo.com.br - tblebedeff@gmail.com

Recebido em 25 de julho de 2014

Aprovado em 05 de novembro de 2014

Revista Educação Especial | v. 28 | n. 52 | p. 365-376 | maio/ago. 2015 